\title{
Space-time mapping of co-working spaces in Cairo: shifting paradigms from openness to technologically controlled spaces
}

\author{
Heba Mourad ${ }^{1 *}$, Zeinab Shafik ${ }^{1}$ and Momen El-Husseiny ${ }^{2}$
}

\author{
* Correspondence: heba.sherif. \\ mourad@gmail.com \\ ${ }^{1}$ Department of Architecture, \\ Faculty of Engineering, Cairo \\ University, Giza, Egypt \\ Full list of author information is \\ available at the end of the article
}

\begin{abstract}
The paper demonstrates how co-working spaces, with their openness ideologies that are not only manifested in sharing space, but also sharing knowledge and generating access to nonhierarchical productive opportunities, are being subsumed into reinforcing neoliberal exclusiveness. The paper questions the openness of coworking spaces that reconciled with the dominant ideologies of 2011 Cairo, setting the stage to the mushrooming of co-working spaces inside Cairo's apartment buildings as zones of relative freedom. Through space-time mapping of the emergence of co-working spaces in Cairo, in addition to interviews with co-workers, co-founders, and managers of co-working spaces, the spatial appropriation and accessibility of co-working spaces are demonstrated. Using content analysis and space syntax analysis, the study differentiates between two paradigmatic shifts in the spatial appropriation of co-working spaces-from democratizing digital infrastructure in the aftermath of 2011, to being subsumed by technological capitalist ventures by the end of 2015 into a closed paradigm, they originally emerged to defy-and compares between the spatial accessibility, visual accessibility, and social diversity of the two waves of co-working spaces. Using Cairo's co-working spaces as a case study, this paper shows how ideologies of openness "neutral" as they may seem, can serve to legitimize exclusiveness, emphasizing how ideas - as men-can be socially located, and serve to legitimize a particular social situation.
\end{abstract}

Keywords: Co-working spaces, Mapping, Openness, Cairo, Spatial appropriation, Spatial accessibility, Space syntax, Visual accessibility, Social diversity, Entrepreneurial urbanism

\section{Introduction}

As the economy shifted from industrial manufacturing to service and knowledge sectors, corporates started articulating their "core purpose" as an organizational and motivational principle to stand out in the market [1]. A corporate's headquarters came to represent not only a functional work environment but an image of the brand's values and ideologies.

(c) The Author(s). 2021 Open Access This article is licensed under a Creative Commons Attribution 4.0 International License, which permits use, sharing, adaptation, distribution and reproduction in any medium or format, as long as you give appropriate credit to the original author(s) and the source, provide a link to the Creative Commons licence, and indicate if changes were made. The images or other third party material in this article are included in the article's Creative Commons licence, unless indicated otherwise in a credit line to the material. If material is not included in the article's Creative Commons licence and your intended use is not permitted by statutory regulation or exceeds the permitted use, you will need to obtain permission directly from the copyright holder. To view a copy of this licence, visit http://creativecommons.org/licenses/by/4.0/. The Creative Commons Public Domain Dedication waiver (http://creativecommons.org/publicdomain/zero/1.0/) applies to the data made available in this article, unless otherwise stated in a credit line to the data. 
Co-working spaces-representing a flexible work style enabled by information and communication technologies-have not only been offering just open work environments, with low physical barriers [2, 3], but also an open work culture that fosters collaborative work, and sharing of knowledge between entrepreneurs [2, 4, 5, 38, 39], giving a sense of meaning through helping out [6].

“The co-working giant's real product isn't office space - it's a new kind of 'corporate culture"' [1].

The open work culture of co-working spaces fosters a language of autonomy and belonging at the same time [1]. It combines "independent" professionals, giving strength and definition to the individual's sense of independence, and providing freedom and flexibility in terms of time/location/communication, within the structure of a coworking community, even if some people do not collaborate at times [5].

Co-working spaces became considered territories that are accessed purposely to construct and maintain network relations and perpetrate a market position [5]. Local interactions at the co-working space would grant members-with good work reputationvisibility to external local firms [4]. Co-working spaces have even been used as experimental solutions after economic crises, to combine venture capitalism with social impact, foster purpose-driven civic institutions; and cultivate entrepreneurship with new civic orientation [7]. Co-working spaces emerged in areas where skilled labour forces and business opportunities existed, within proximity to universities and research centers [8] or within proximity to business facilities [9].

High tech parks like "Smart village" represented the former model of open work environments in Cairo-prior to co-working spaces; in the same sense of Thrift's interpretation of softer knowledge capitalism and open innovation [10]. The open work environment in "Smart village" was represented in gathering information technology companies and their different supporting institutions in one place [40], to decrease physical barriers and build a community of work. Although "Smart village" was framed in 2001 as an "open" work environment, the state's gated "Smart village" satellite city represented a typical neoliberal landscape of exclusion in Cairo.

The paper questions the openness of co-working spaces in Cairo, that emerged from below-inside apartment buildings-defying the contemporary form of neoliberal globalization, materialized in exclusive "prestige" projects, which resulted in a social and economic disconnection between the majority of people and the development of their city [11]. The study demonstrates how co-working spaces, with their openness ideologies, that are not only manifested in sharing space, but also in sharing knowledge, and generating access to nonhierarchical productive opportunities, are being subsumed into reinforcing neoliberal exclusiveness as the prior tech parks.

\section{Paradigm shifts in architectural theory and place typologies}

Paradigm shifts are the essence of the development in any scientific field [12]. According to Kuhn [12], the development in any scientific field, and the understanding of any phenomenon happens through reaching a common intellectual framework/paradigm, and when anomalies increase between what the paradigm predicts and what it 
reveals-by observation or experiments-researchers start to question the paradigm itself and reach a new paradigm that better explains the phenomenon.

Traditional place typologies are witnessing a paradigm shift in the 21st century; boundaries are blurring between first places: home, second places: work, and third places $^{1}$ : public places on neutral ground where people can gather and interact [14]. Coliving $^{2}$ is combining elements of the first and second places, co-working ${ }^{3}$ elements of the second and third places, and co-mingling ${ }^{4}$ elements of the first and third places [14].

This paradigm shift in place typologies (blurring traditional place boundaries) highlights the importance of tacit knowledge, social interactions, networks, and the spatial dimension of innovations in the knowledge economy of the post-industrial global city [14] where being in the "right network" matters more than being in the "right place" [15]. It also highlights the value shift of access over ownership, due to economic realities, and environmental pressures together with the effectiveness of information and communication technologies [16].

Work spaces, in particular, have been breaking from the physical constraints of cellular spaces in office buildings to an almost complete liberation from space, in a nonterritorial environment. Employees simply need to "connect to work"; not necessarily needing the office. The office in the 21st century has become an opportunity for providing "face-to-face" interaction and collaboration, getting rid of cubicles and adding social support spaces and hospitality services to aid knowledge transfer and communication. Global companies like Google, Yahoo, and Samsung started capitalizing on man power and innovation, by designing their headquarters to create chance encounters [17]. New work styles like teleworking reduced the average office space per employee, from $30 \mathrm{~m}^{2}$ in 1995 to $20 \mathrm{~m}^{2}$ in 2013 [18].

The work place evolved from a physical place for administrative duties, after the industrial revolution, to become a place of power and decision making after the invention of the telephone and the telegraph, where the work itself was mainly done on factory floors [18]. The first efficient, purpose-built office spaces-that was designed by the American Engineer, Frederick Taylor, in the beginning of the 20th century-crowded workers in open environments, while bosses monitored their work from private offices and established authority.

Socialist views of the 60s transformed work arrangements to depend on functions rather than organizational hierarchy. In 1968, Herman Miller introduced the office cubicles known at the time as "action office", with the first modular furniture system with low dividers and flexible work surfaces. While in the 1980s, the cubicle concept was taken to the extreme when the ranks of middle managers swelled; the divider walls became higher restricting natural light and blunting collaboration. The link between workplace design and organizational performance since the 1980s created some

\footnotetext{
“"Third places": introduced by Ray Oldenburg in 2000, continuing his work about the importance of informal public gathering places [13]

${ }^{2}$ Co-living provides shared accommodations and working areas to entrepreneurs [14].

${ }^{3}$ Co-working creates an atmosphere conducive to work and network in order to favor the exchange of knowledge and to foster collaboration opportunities [14]

${ }^{4}$ Co-mingling mixes shared apartments and shared common spaces providing social interactions and networking opportunities between its residents [14].
} 
pressing themes; among them were new work styles, the continuing expansion of IT and its effect on communication, the internationalizing of branding, and sustainability [19].

In Cairo, the concept of office buildings was not known until the 20th century. Initially, before functional office buildings emerged, offices would occupy other building types, like old factories or residential buildings [20]. The first-designed office buildings in Cairo had cellular space plan designs, and the building would be owned by a single company/owner, like Misr insurance company office building by the architect Mahmoud Riad in 1948 [20]. More democratic work spaces started emerging in Cairo from the 1980s, occupying office buildings with rentable spaces, open floor plans, and advanced facilities and services, like "Nile towers" and "Cairo plaza" office buildings. Nevertheless, social connections and nepotism formed a great part in Cairo's work culture, as unemployment started increasing among highly educated youth in Cairo, in addition to insufficient productive opportunities [21].

\section{Methods}

The specificity of the rise of co-working spaces in Cairo at a time of political temporality post 2011 was explored using space-time mapping of co-working spaces on the

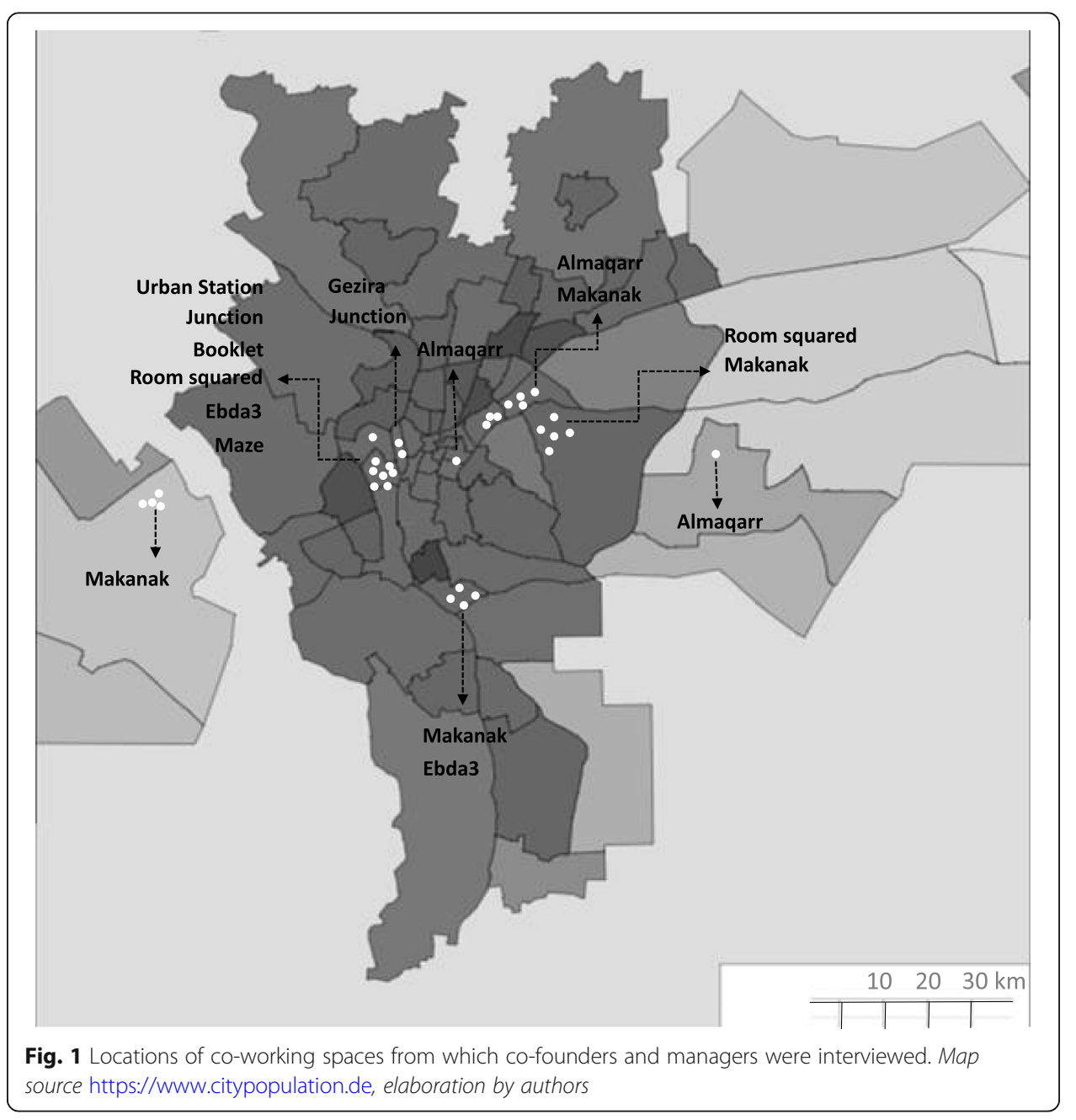


course of 3 years (from 2017 to 2020), questioning their openness ideologies, which are not limited to sharing space, but also sharing knowledge, and generating access to nonhierarchical productive opportunities.

Data was collected from virtual and physical mediums; Google maps, virtual social media platforms of co-working spaces, and visits to the physical spaces, followed up by semi-structured interviews. Different questions were posed for different groups of people: co-workers, co-founders, and managers of co-working spaces. Thirty interviews were conducted on the course of 4 months from October 2019 till February 2020. The interviews were recorded with the prior verbal consent of the participants.

The co-workers sample of informants was a purposeful sample of 10 informants; to include the two categories of co-workers explored: students and professionals. Cofounders and managers sample comprised 20 informants from 10 pioneering coworking spaces in Cairo that covered greater Cairo with multiple branches as shown in Fig. 1 and were recurrently mentioned during interviews: "Almaqarr", "The Junction", "Caravan", "Booklet", "Room squared", "Urban station", "Gezira sporting club coworking space", "Ebda3", "Makanak", and "Maze". The co-working spaces used in the study were founded in the period from 2012 to 2018 as shown in Table 1.

The evolution of spatial appropriation and accessibility of co-working spaces in Cairo was analyzed using content analysis, in addition to space syntax analysis, based on Sassen's identification of an open city paradigm as "the ability of people to hack into the city from ground up", where hacking - in general-refers to the process of clever appropriation of existing technologies or infrastructures, or bending the logic of a particular

Table 1 Year of establishment of co-working spaces used for the study. Source: elaboration by the authors

\begin{tabular}{lll}
\hline Name & Branches & Year \\
\hline 1. 1. 1. 1. 1. 1. AlMaqarr & Heliopolis & 2012 \\
& Heliopolis & 2014 \\
& Downtown & 2017 \\
& Al Gouna & 2017 \\
& Heliopolis & 2019 \\
& 5th settlement & 2019 \\
2. 1. The Junction & Dokki & 2017 \\
& Zamalek & 2019 \\
3. Booklet & Dokki & 2013 \\
4. Caravan & Dokki & 2015 \\
5. 1. Room squared & Dokki & 2018 \\
& Madinet Nasr & 2018 \\
6. Urban station & Mohandeseen & 2016 \\
7. Gezira club & Zamalek & 2020 \\
8. 1. 1. Ebda3 & Dokki & 2012 \\
& Dokki & 2015 \\
9. 1. Makanak & Maddi & 2019 \\
10. Maze & 12 Branches in: Maadi, 6th of October, Heliopolis, Madinet Nasr & 2015 \\
\hline & Madinet Nasr, Mohandeseen, Maadi & 2018 \\
& Dokki & 2015 \\
\hline
\end{tabular}


system beyond its intended purposes or restrictions [22]. Visual accessibility, spatial accessibility, and social diversity of co-working spaces were compared from 2011 to 2015 to differentiate between the accessibility of co-working spaces at these two stages, according to Abdel-Rasoul et al.'s [23] conceptual framework from the publicness rights of any given public space.

\section{Results: space-time mapping of co-working spaces in Cairo}

\section{Spatial appropriation shifts}

The study differentiates between the spatial appropriation of two waves of co-working spaces in Cairo, at a time of political temporality post 2011 and by the end of 2015, with the emergence of global franchise of co-working spaces in Cairo. Nevertheless, the openness ideologies presented by the global co-working spaces in 2015, reconciled with the dominant ideologies in Cairo post 2011, reflected by a spike in the number of coworking spaces (of both waves) in 2016, reaching double the number of co-working spaces in 2015 as shown in Fig. 2. "Doing what you like is freedom" was the kind of slogans andcatchwords used on the co-working spaces' social media platforms.

Nonetheless, the same open environment of co-working spaces that allowed the coexistence of different waves of co-working spaces, with a variety of activities and services in the first place, created legal problems due to the ambiguity around the purpose behind some of these co-working spaces. This ambiguity in return allowed room for inequality regarding which co-working space was given permission to operate, and this is where power of relationships and connections came into play.

Mapping representation of co-working spaces from 2011 to 2014-in white borders as shown in Fig. 3-demonstrates that post 2011, co-working spaces integrated within the urban setting of the city of Cairo-28\% of the co-working spaces emerged in Dokki, 22\%

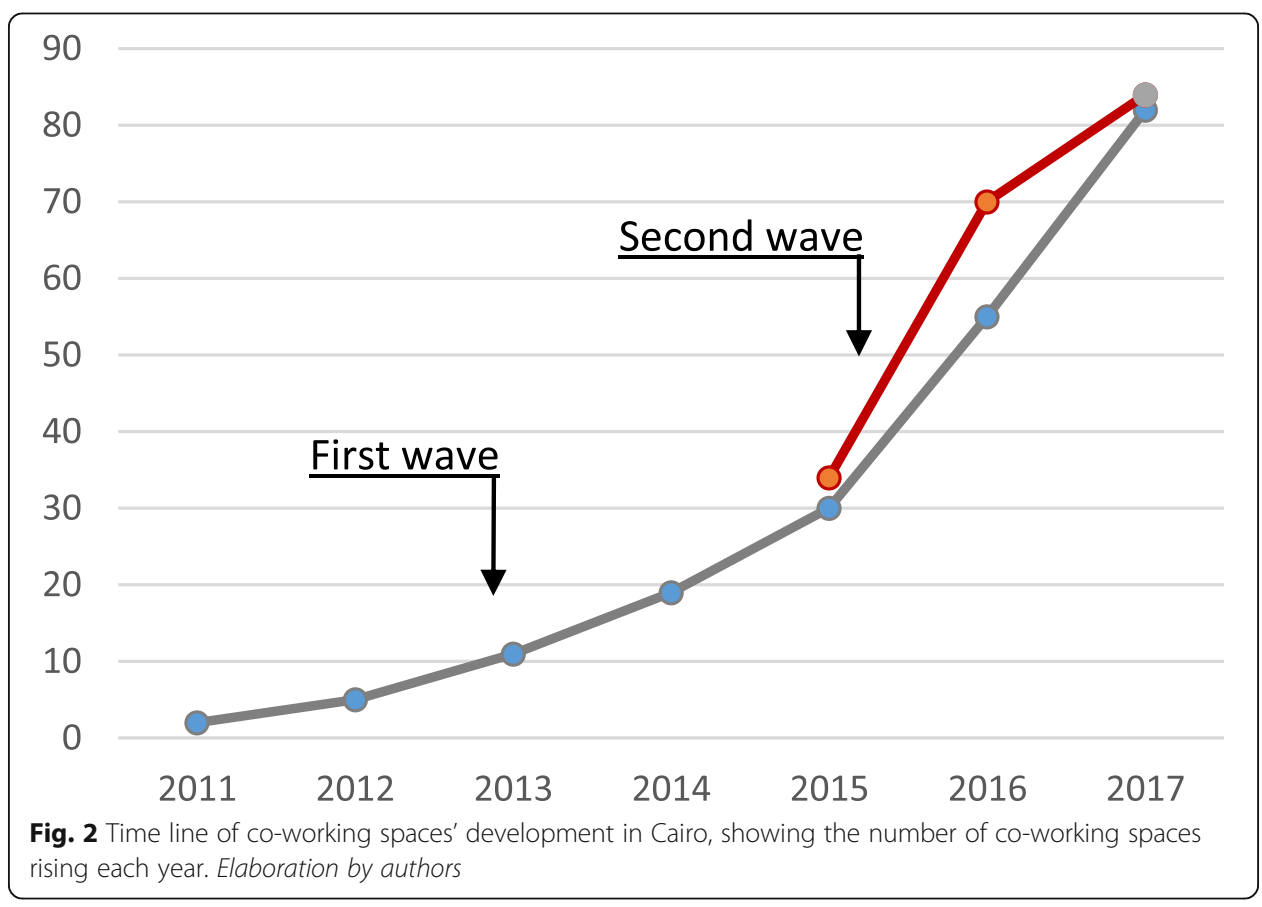


in Nasr city, 22\% in Heliopolis and Al Wayli districts, 22\% in Maadi, and 6\% in Downtown. The first wave of co-working spaces spread with proximity to main public university campuses that could no longer afford to accommodate public student life inside its campuses [24]. One of the earliest co-working spaces that was founded in 2012 was even named "Almaqarr", meaning the headquarters in Arabic; representing the consistent need to gather interested partners for collaborating on extra student activities.

Youth, the ordinary people - not necessarily having business backgrounds-started renting apartments within residential buildings to create the first wave of co-working spaces, before they were officially recognized by the state, but they would find a gap in the states' system and register under other categories, such as training centers. The term "co-working space" was not recognized by the co-founders themselves before 2014. Minimal spatial appropriation of these apartment buildings would be carried out; with respect to these youth's modest means. Spatial appropriation could include demolishing some walls, enlarging space openings for adequate sunlight to enter, and most importantly introducing a new layer of internet infrastructure needed for working in the 21st century.

After 2015, greater investments-70,000/ 80,000 Egyptian pounds per month-were put in co-working spaces as global corporates including: Google, Microsoft, and Vodafone,

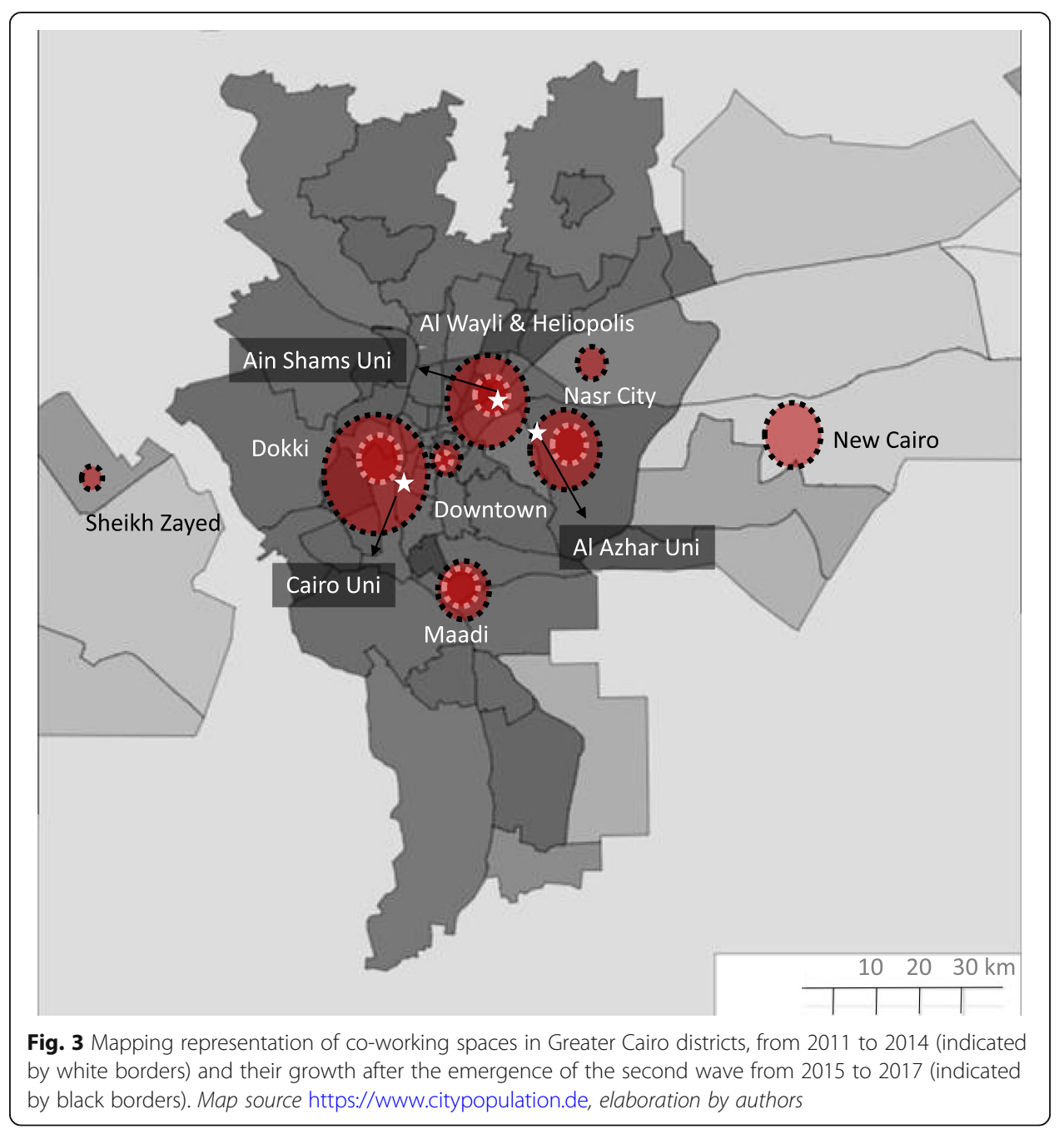


Table 2 Shift in spatial appropriation of co-working spaces in Cairo. Source: elaboration by the authors

\begin{tabular}{lll}
\hline & 1st Wave (2011) & 2nd Wave (2015) \\
\hline Spatial & Bottom-up & Top-down \\
appropriation & With proximity to universities within & Extended to new satellite cities, not necessarily close \\
& the City of Cairo. & $\begin{array}{l}\text { Occupinersities. } \\
\text { Inside residential apartment buildings. }\end{array}$ \\
& & Office buildings and business parks. \\
\hline
\end{tabular}

invaded the co-working scene. These bigger investments provided a wider range of renting options for the second wave of co-working spaces; they allowed renting spaces in more prime locations, specifically designed for working, within office buildings. The Regus co-working global network for example that has 3000 locations in 120 countries, promoted its prime locations in Nile city business towers on its website as "one of the most prestigious business addresses in the Egyptian capital next to the Nile". The mapping representation of co-working space expansion from 2015 to 2017-in black boarders as shown in Fig. 3-shows that co-working spaces have expanded all over Greater Cairo (reaching 31\% in Dokki, 23\% in Helipolis and Wayli, 19\% in Nasr city, 9\% in Maadi, 4\% in Downtown), extending to new satellite cities (12\% in New Cairo and 3\% in Sheikh Zayed).

Table 2 compares the spatial appropriations of the two waves of co-working spaces from bottom-up inside apartment buildings with proximity to universities within the city of Cairo, to top-down inside complex administrative buildings reaching new satellite cities. The following sections demonstrate how the shift in co-working spaces' spatial appropriation was affecting the spatial accessibility, visual accessibility, and social diversity of the co-working spaces.

First wave accessibility (2011)

Spatial accessibility

Space syntax analysis ${ }^{5}$ of Greater Cairo, shown in Fig. 4 (conducted by axial analysis ${ }^{6}$ ), demonstrates how the co-working spaces spread in more spatially integrated areas in Cairo, like Dokki, Heliopolis, and Nasr city-calculated by the closeness of each segment in the map to all other segments [26]_indicating that areas where co-working spaces were emerging have higher pedestrian flow rates and attract retail land uses to take advantage of the passing which in turn increases the original flows [25].

Zooming in on one of the highly concentrated districts in co-working spaces in Cairo, Dokki district, Fig. 5 shows how co-working spaces spread within transit-oriented areas (with a metro station) that indeed had youthful flows; emerging within walking distances from universities. Nevertheless, co-working spaces had controlled public access point; access is not free of charge.

\section{Visual accessibility}

The first wave of co-working spaces have not been limited to main streets in Cairo, with greater spatial exposure as demonstrated in Fig. 6. Even when co-working spaces exist in main streets, no apparent architectural or urban change would be noticed outside the co-working space as shown in Fig. 6 as well. From the street level, hidden

${ }^{5} \mathrm{~A}$ quantitative method that describes patterns of spatial relationships [25].

${ }^{6}$ Axial analysis is a way of analyzing a spatial layout represented by an axial map [25]. 


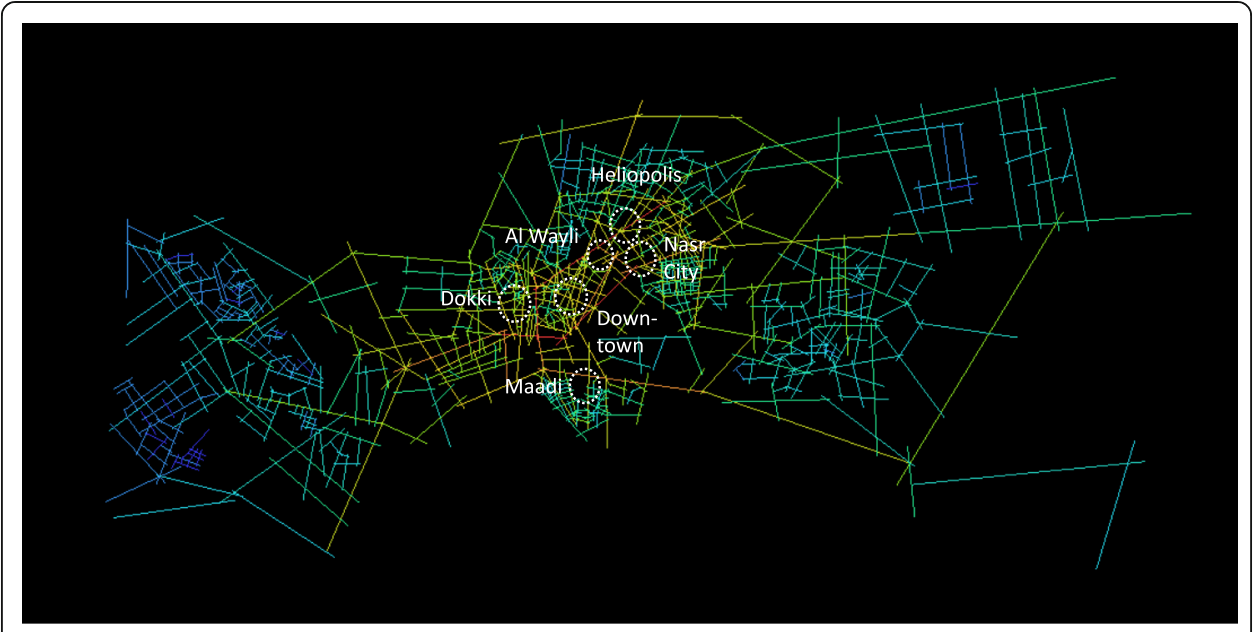

Fig. 4 Space syntax integration analysis $(R n)$, representing the spatial integration of the areas where coworking spaces emerged in Cairo post 2011 till 2014; red color indicates higher values of integration, blue color indicates segregation and lower values. Elaboration by authors

behind the barriers of apartment buildings, these co-working spaces could only be recognized from the gatherings of youth who came pouring in from nearby universities, seeking something different. With the increasing demand on co-working spaces, cofounders started seeking more visually accessible spaces from street level and occupying bigger commercial units in ground floors, towards gradually increasing permeability and space exposure of the co-working spaces.

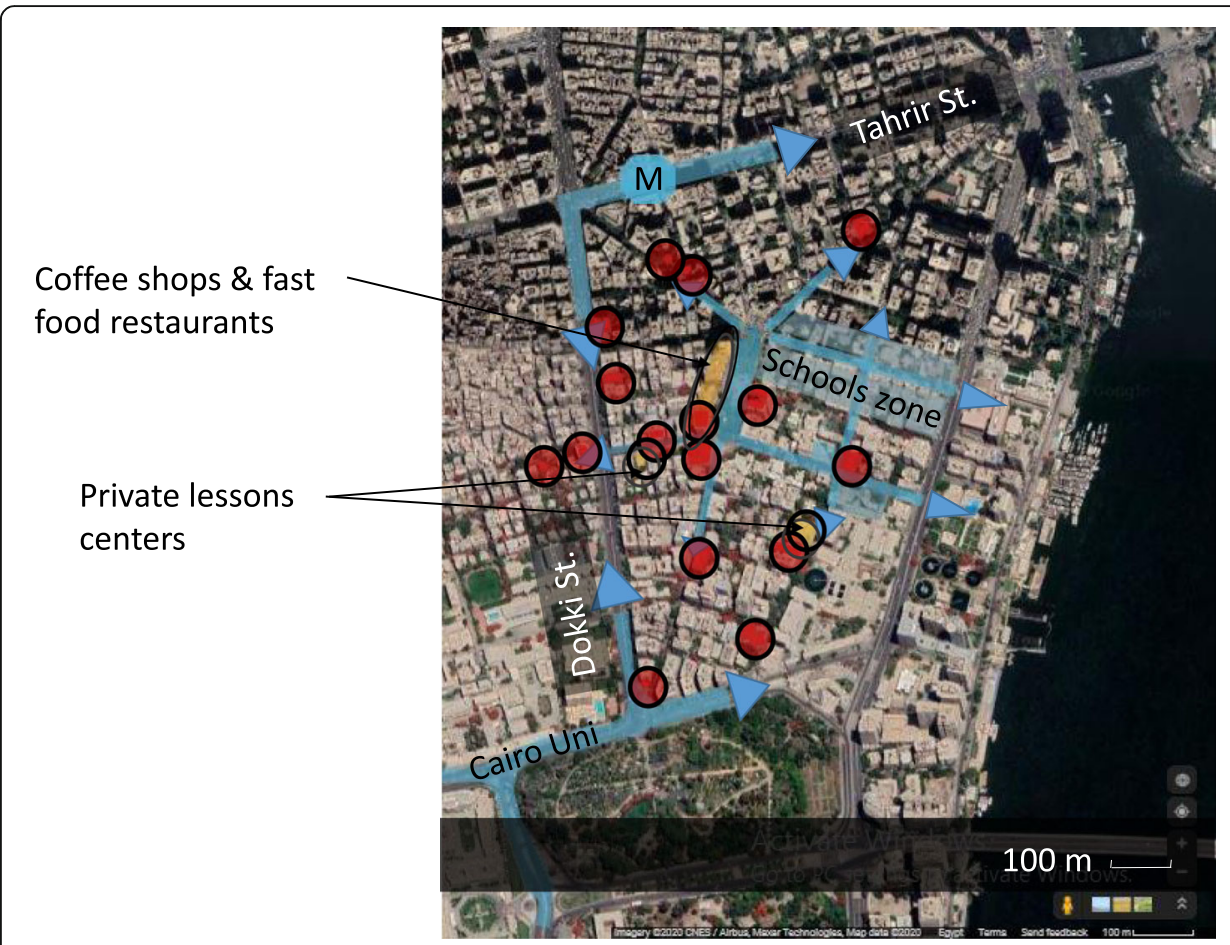

Fig. 5 Youth flow to co-working spaces and presence from universities, schools, public transit, and private lesson centers in Mesaha area in Dokki (largest concentration of co-working spaces). Map source https:// www.google.com/maps, elaboration by authors 

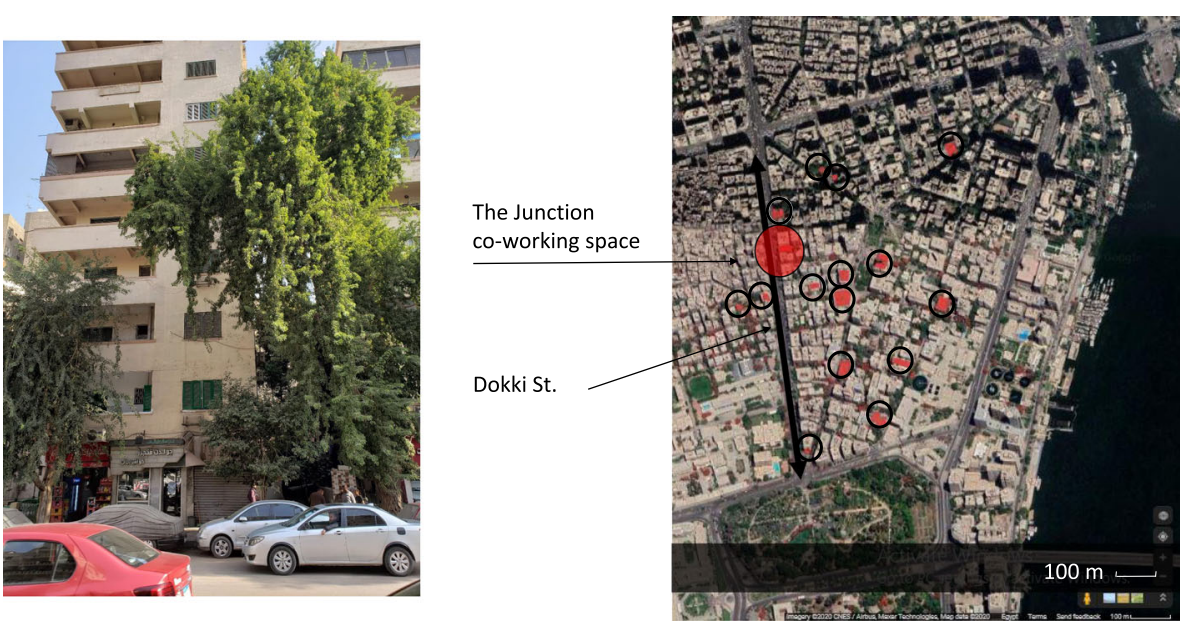

Fig. 6 The residential building (on the left) that accommodates "The Junction co-working space"; one of the co-working spaces in Dokki area (on the right): the junction co-working space. Map source https://www. google.com/maps, elaboration and picture captured by authors

\section{Social diversity}

Co-working spaces foster collaborative work; having an "open" work setting, mostly non-territorial, and work spaces were divided activity based not position based as shown in Fig. 7. Youth represent the dominant social group; co-founders, co-workers, managers and employees at co-working spaces have ages ranging from 20 to 39. Both genders-male and female-are represented. Co-workers are mostly students, freelancers, and entrepreneurs. The variety of activities is demonstrated with statements like "We are a co-working space where you can work, study, read, give and attend sessions and workshops and even meditate" (The Junction Facebook page).

Although co-working spaces of the first wave demanded entrance fees for their services, the fees were affordable for a wide range of youth/students (starting from 5 EGP per hour or 15 EGP for the whole day). "Caravan" co-working spaces provided recording and rehearsing studios that were more accessible to youth from limited/exclusive studios of Downtown Cairo (known for being Cairo's cultural hub), attracting even bigger corporates in the media fields later on. Other co-working spaces like "Booklet" and "ebda3" (meaning creativity in Arabic) made parallel book fairs, at the same time of the main national book fair, with cheaper prices, to make literature more accessible to a wider public of youth.

Socially responsible capacity building initiatives like "Career Advancers" -that emerged within this network of co-working spaces, aside from sharing available job opportunities on their website and social media pages for a wider audience, they encouraged standing up to discriminating job offers; that targeted a specific gender/ certain university graduates over others, etc.; providing alternative opportunities for productive encounters, and nonhierarchical empowerment.

\section{Second wave accessibility (2015)}

\section{Spatial accessibility}

Although co-working spaces were expanding all over Greater Cairo, increasing the range of business/ initiative mobility, not limiting their reach to a certain neighborhood 


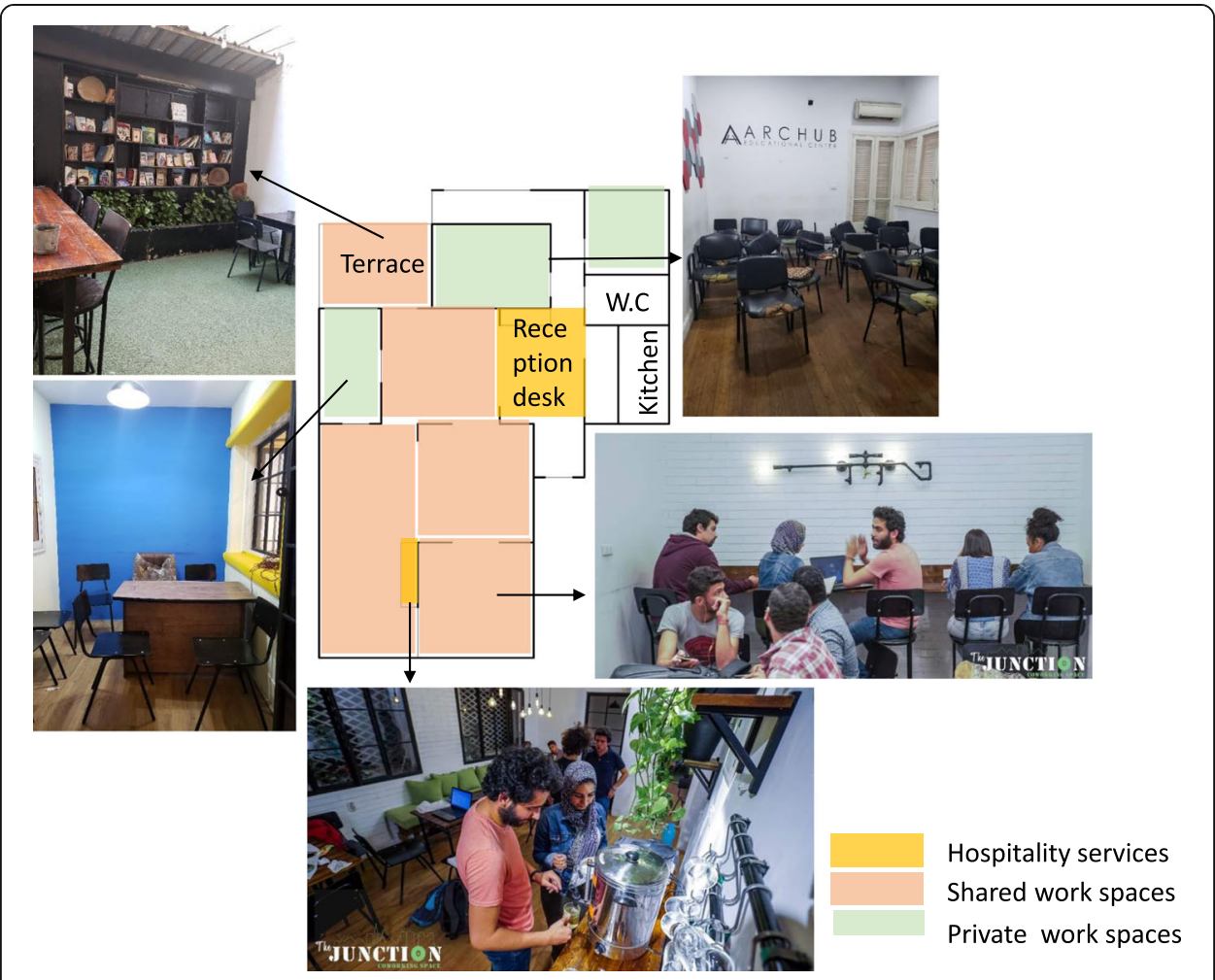

Fig. 7 A representation of co-working spaces; work environment fostering collaborative work: The Junction co-working space, elaboration by authors

or community; they were gradually rising in new satellite cities (Sheikh Zayed, and New Cairo), that are more spatially segregated-as demonstrated in space syntax analysis in Fig. 8-and car-dependent areas.

Even when co-working spaces were expanding within the same spatially integrated neighborhoods, choice of location differed from those of the first wave of co-working

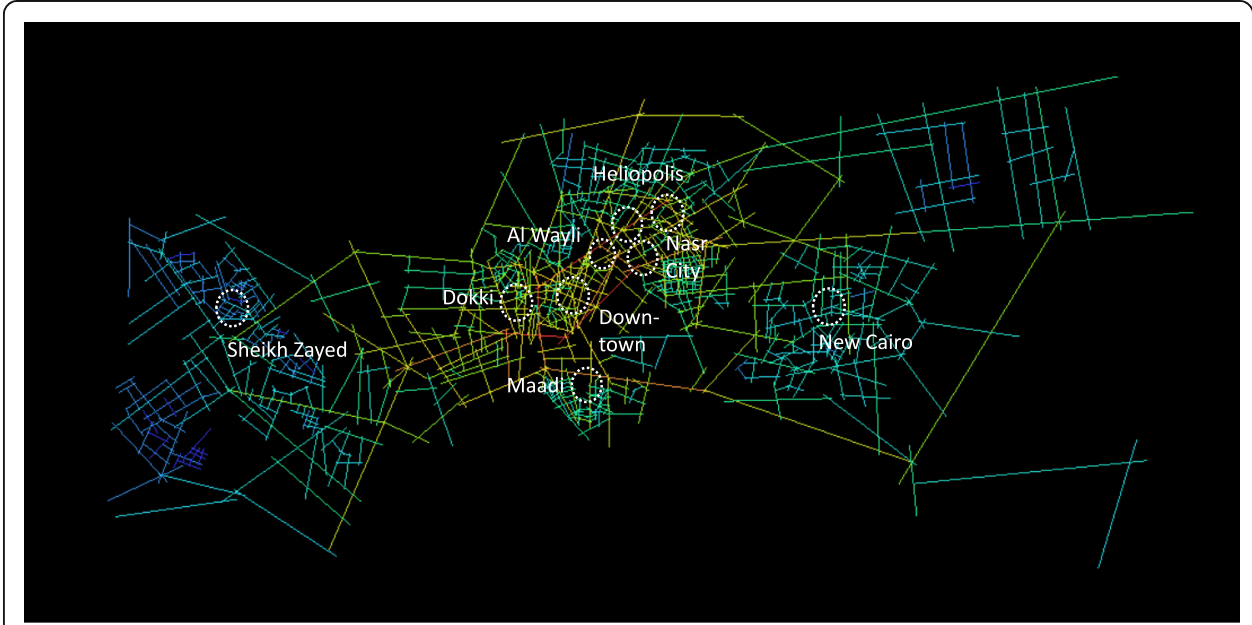

Fig. 8 Space syntax integration analysis (Rn); representing the expansion of co-working spaces till 2017, and the spatial segregation of new areas from 2015; red color indicates higher values of integration; blue color indicates segregation and lower values. Elaboration by authors 

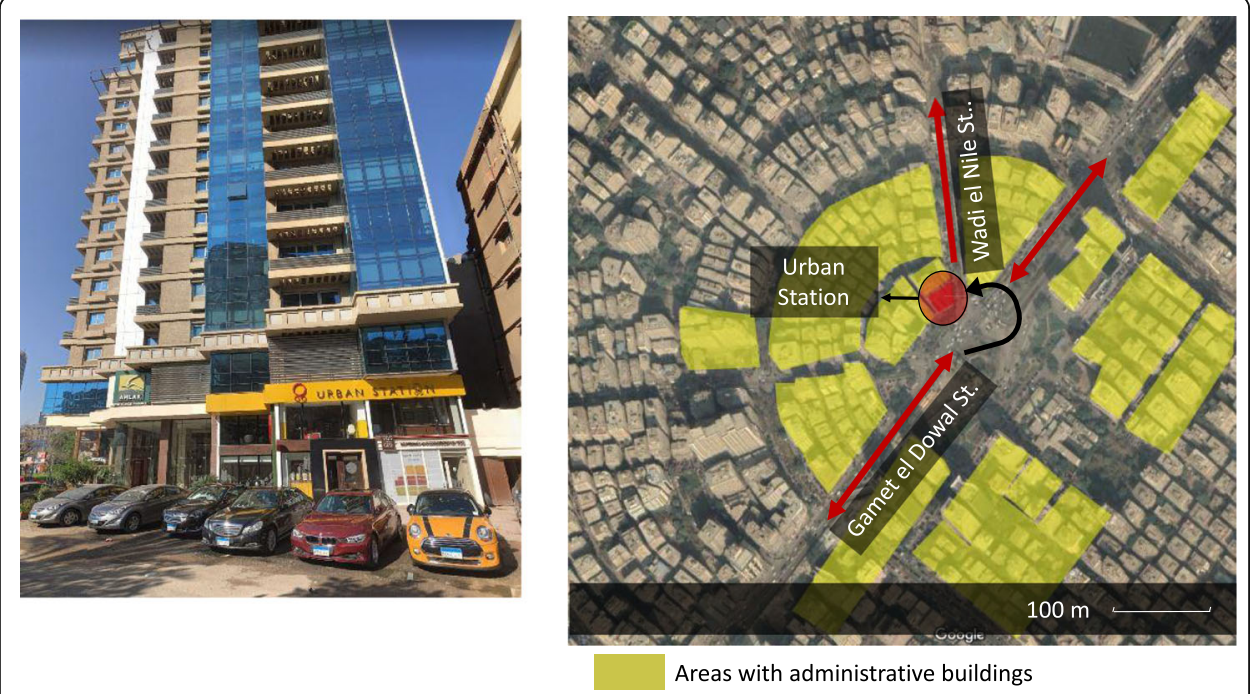

Fig. 9 Administrative building (on the left) accommodating Urban station co-working space; situated in an administrative area on Gamet el Dowal and Wadi el Nile Street (on the right) in Mohandessen area near Dokki area, in Cairo. Map source https://www.google.com/maps, elaboration by authors

spaces. The second wave of co-working spaces started occupying zones with more controlled public access points like the Greek campus and Gezira sporting club. The Greek campus is a "gated" high tech park integrated within the city center in Downtown Cairo, and home to more than 130 start-ups. "Gezira sporting club" is an exclusive membership "elite" club. A co-working space would create even more controlled spaces within these controlled premises-needing further membership-to provide "better" spaces for working and collaborations.

\section{Visual accessibility}

The co-working spaces of the second wave started becoming more visually accessible, having more spatial exposure and permeability. Figure 9 demonstrates the approach to The Urban station co-working space; exposed to two important streets occupying the ground floor of a complex administrative building with a permeable façade. Standardized designs (interior and exterior) started to be noticed as well as shown in Fig. 10. As technological global firms started rebranding co-working spaces in Cairo.

\section{Social diversity}

Although co-working spaces of the second wave became more spacious ${ }^{7}$, including more hospitality services to support collaborative work in an open work environment, like coffee shops as shown in Fig. 11, the mobile applications that were used for sharing knowledge and acquiring services in the first wave were becoming deployed by some co-working spaces of the second wave to control access. Certain zones started to be confined to members only, and access to these areas would be through scanning members' mobile phones through added electronic gates.

${ }^{7}$ The area of a typical co-working space from the second wave would be around 800-1000 $\mathrm{m}^{2}$ compared with $250 \mathrm{~m}^{2}$ in the first wave of co-working spaces. 


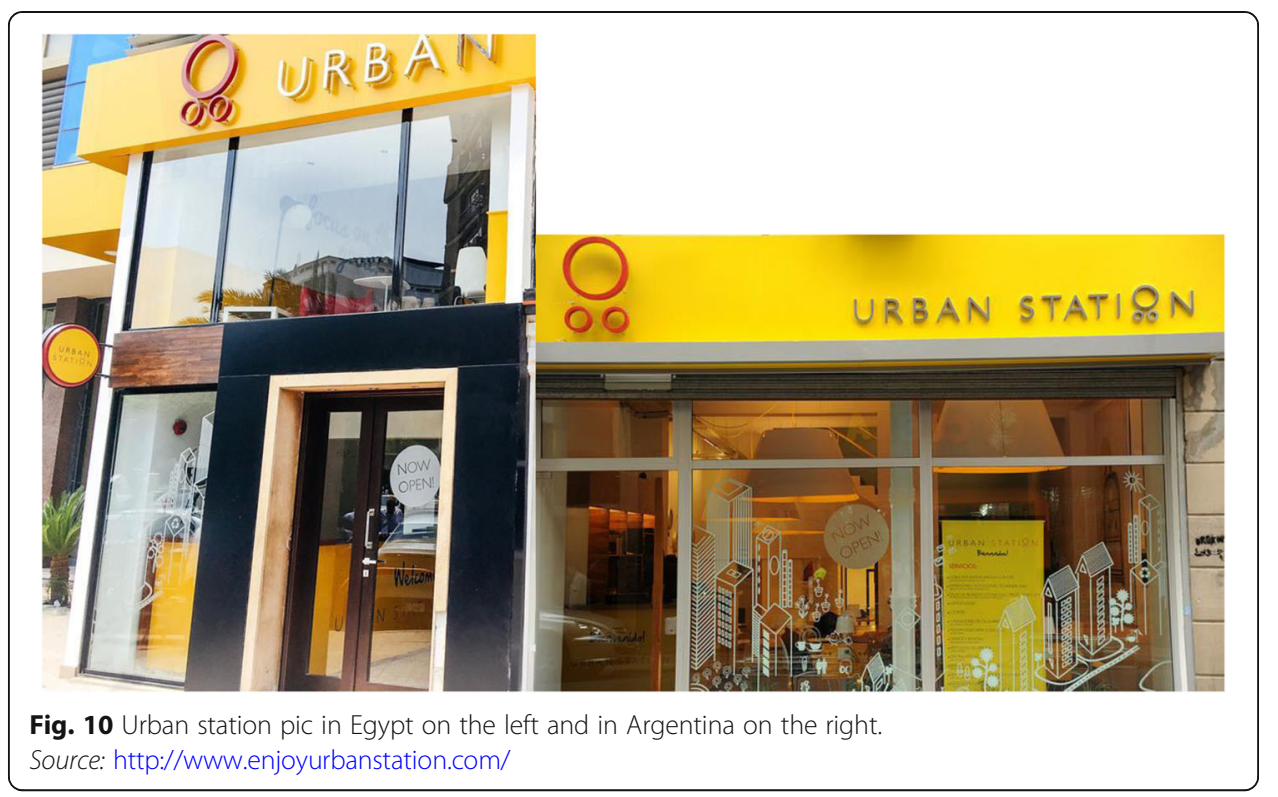

As the second wave of co-working spaces invested in prime locations -in comparison with the former wave of co-working spaces, entry fees were raised consequently. Coworking spaces started charging around 2000-3000 Egyptian pounds per month for the use of the shared spaces and "no student would pay this amount" as indicated by founders and co-workers of the first wave. Students could no longer afford this second wave of co-working spaces that were targeting a certain social class of entrepreneurs. The variation of entry fees among different branches of the same co-working space, depending on the socioeconomic level of the neighborhood, shows as well how capital forces started undermining people's accessibility to the co-working spaces.

\section{Discussion}

Space-time mapping of co-working spaces in Cairo demonstrates a paradigmatic shift; from openness in the aftermath of 2011, to being controlled by technology investment capital, by the end of 2015. Despite the spatial enclosures and visual barriers inside apartment buildings, the first wave of co-working spaces was more accessible than the second one, as shown in Table 3, enabling youth to express their individuality and have active presence in the public life of the city [27].

By the collaborative consumption/sharing of apartments (high assets and underutilized) in political temporality of Tahrir square post 2011-which expanded youth imaginative horizons, and empowered them to utilize the city at its full potential-youth were able to hack into the city and modify it, "access" these new urban commons, avoid high real estate investments, generate nonhierarchical productive opportunities, and find an alternative to the upscale coffee shops that provided young upper middle class professionals with new forms of self-presentation from mid 1990s onwards and played a great role in shaping Cairo's up-to-date exclusive modernity [11].

${ }^{7}$ The area of a typical co-working space from the second wave would be around 800-1000 $\mathrm{m}^{2}$ compared with $250 \mathrm{~m}^{2}$ in the first wave of co-working spaces. 


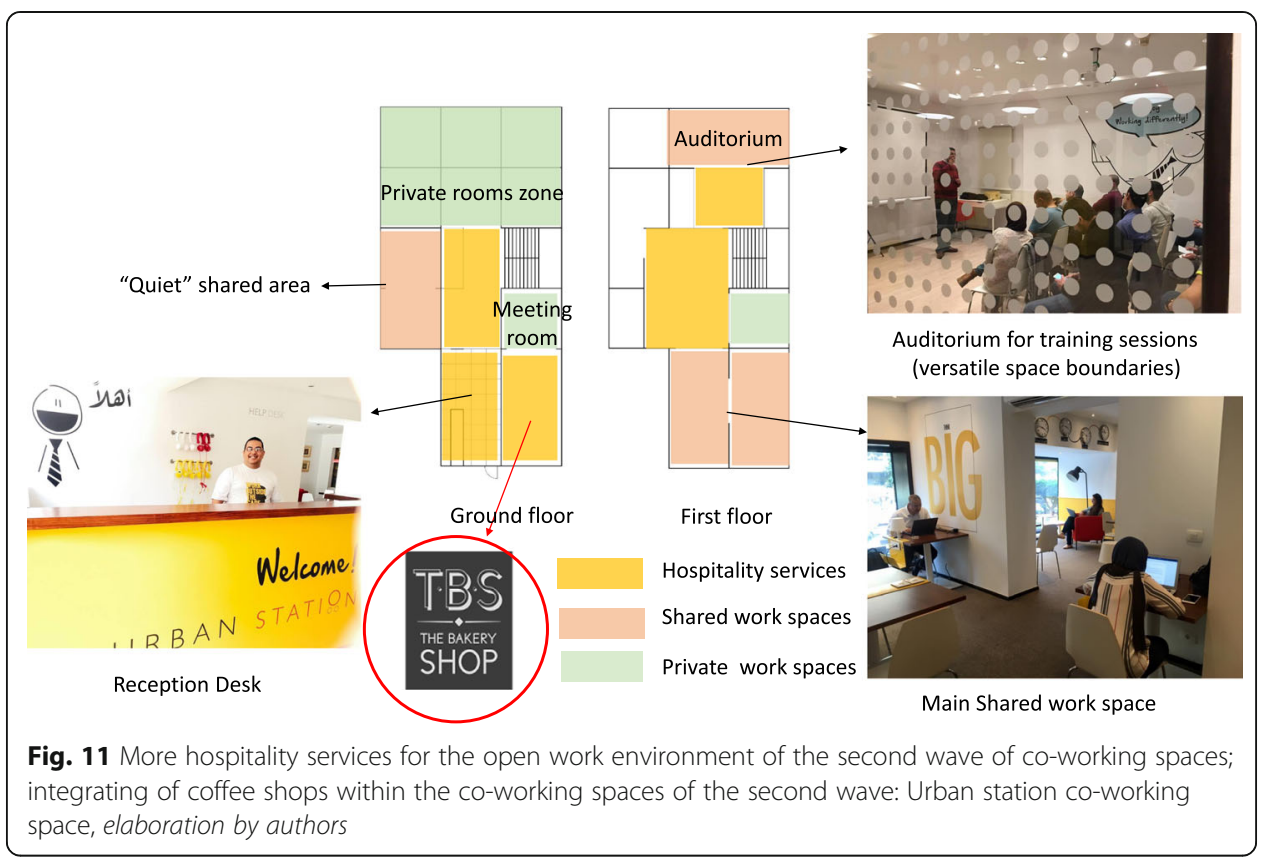

On the other hand, the spatial selective nature of the second wave of co-working spaces, by the end of 2015-as higher corporate investments allowed more renting options-limited youth's access to the co-working spaces. While becoming more visually accessible, with more space exposure and permeability from the street level, students and the wider majority of youth could no longer afford to access these co-working spaces.

The usage of electronic gates, in providing membership zones demonstrate how technology shifted from being in dialogue with the people-enabling open knowledge dynamics and generating nonhierarchical productive encounters-to being in command, unlike the open city framework that is never complete and can constantly be made for better or for worse [28], the same way "smart city" narratives became controlled by high tech firms, where "Smart urbanism" is subsumed into an entrepreneurial mode, and linked with austerity measures [29], where benefits to the wider citizenry are secondary to the attraction of multinational corporations and foreign investments (Wiig, 2015) [30].

While the narrative of entrepreneurialism has been viewed in the light of the ideological dimension of globalization, where cities' view of "economic" globalization is

Table 3 Comparison between co-working space accessibility of the first and second waves. Source: elaboration by the authors

\begin{tabular}{lll}
\hline & 1st wave (2011) & 2nd wave (2015) \\
\hline Spatial & More integrated & More segregated \\
accessibility & Walkable/transit oriented & More car dependent \\
& Moderately controlled public access points (not & More controlled public access points (within \\
& free of charge) & gated areas) \\
Visual & Less spatial exposure & More spatial exposure \\
accessibility & More barriers & More permeable \\
Social diversity & Affordable for a wider socioeconomic class & $\begin{array}{l}\text { Affordable for an exclusive socioeconomic } \\
\text { class }\end{array}$ \\
\hline
\end{tabular}


advanced through the state's adaptation to entrepreneurial policies that make it easier for the work of globalization to be done [31]. The spatially selective nature of entrepreneurial urbanism within cities and the shift it creates in the state's role of urban redevelopment have been questioned [32].

The study builds upon Lorne's argument that the "open" spaces of co-working are unevenly experienced, exclusionary, and reinforce hierarchies in the name of networking, community, and innovation [7] and confirms the possibility of hijacking sharing ventures by capitalist ventures under the name of "sharing" [16], which can be identified when these ventures-under the name of sharing-no longer respond to the authentic needs of the community and become not accessible to all [16], like the example of Airbnb (the real estate sharing venture), as their listings were used as a tool for landlords to evict low-wage renters in the city [33] and the decline in urban commons [34].

The study does not overlook the importance of generating profit from co-working spaces to secure their existence. It only seeks to highlight the importance of establishing democratic control over the deployment of the profit through urbanization, without jeopardizing urban commons, by socialization of profit production and distribution, since much of the corruption attached to urban politics result from the relation between those who produce the products and those who appropriate it for private gain [35].

\section{Conclusions}

The paper demonstrates how openness ideologies of co-working spaces-that reconciled with the dominant ideologies in Cairo post 2011-mobilized from below, inside apartment buildings with proximity to public universities, were later subsumed by technological global companies by the end of 2015 into profit-making agendas, putting more investments in prime locations within complex administrative buildings.

Even though co-working spaces were acquiring more space exposure and permeability from the street level, they were becoming more spatially segregated, with more controlled public access points like gated technological parks, and the wider majority of youth could no longer afford to access.

Using Cairo's co-working spaces as a case study, this paper shows how ideologies of openness can serve to legitimize exclusiveness. It shows how ideas-as men-are socially located, and can be witnessed when ideas serve to legitimize a particular social situation [36], emphasizing why 'ideologies 'neutral' as they may seem need to be questioned and must not go unchallenged" (Foucault, 1975) [37].

Acknowledgements

Authors would like to thank the co-workers, managers, and co-founders of co-working spaces who shared their valuable time and knowledge to participate in the study.

\section{Authors' contributions}

HM performed the space-time mapping of co-working paces and interviews, analysed and interpreted data using space syntax and content analysis, and was a major contributor in writing the manuscript. MH provided essential literature, participated in research design, and contributed in reviewing related studies. ZS reviewed paper structure, results, and data representation. The authors read and approved the final manuscript.

Funding

Not applicable 


\section{Declarations}

\section{Competing interests}

The authors declare that they have no competing interests.

\section{Author details}

${ }^{1}$ Department of Architecture, Faculty of Engineering, Cairo University, Giza, Egypt. ${ }^{2}$ Department of Architecture, School of Sciences and Engineering, The American University in Cairo, Cairo, Egypt.

Received: 30 June 2021 Accepted: 19 October 2021

Published online: 03 December 2021

\section{References}

1. Lewis-Kraus G (2019) The rise of the we working class. Available via https://www.nytimes.com/interactive/2019/02/21/ magazine/wework-coworking-office-space.html. Accessed 26 June 2021.

2. Deijl C (2011) Two heads are better than one a case study of the co-working community in the Netherlands. Erasmus University Rotterdam, Department of Economics Available via http://hdl.handle.net/2105/10074. Accessed 16 July 2020

3. Weijs-Perrée M, van de Koevering J, Appel-Meulenbroek R, Arentz T (2019) Analysing user preferences for co-working space characteristics. Build Res Inf 47(5):534-548. https://doi.org/10.1080/09613218.2018.1463750

4. Capdevila I (2013) Knowledge dynamics in localized communities: coworking spaces as microclusters. Available via https://ssrn.com/abstract=2414121. Accessed 17 August 2018.

5. Gandini A (2015) The rise of coworking spaces: a literature review. Ephemera 15(1):193-205

6. Spreitzer G, et al (2015) Why people thrive in coworking spaces. Available via https://hbr.org/2015/05/why-peoplethrive-in-coworking-spaces. Accessed 6 November 2017.

7. Lorne C (2020) The limits to openness: co-working, design and social innovation in the neoliberal city. Econ Space 52(4): 747-765

8. Mariotti I, Pacchi C, Di Vita S (2017) Co-working spaces in Milan: location patterns and urban effects. J Urban Technol 24(3):47-66. https://doi.org/10.1080/10630732.2017.1311556

9. Fiorentino S (2019) Different typologies of 'co-working spaces' and the contemporary dynamics of local economic development in Rome. Eur Plan Stud 27(9):1768-1790. https://doi.org/10.1080/09654313.2019.1620697

10. Thrift N (2006) Re-inventing invention: new tendencies in capitalist commodification. Econ Soc 35(2):279-306. https:// doi.org/10.1080/03085140600635755

11. De Koning A (2009) Global dreams: space, class, and gender in middle-class Cairo. The American University in Cairo Press, Cairo, New York.

12. Kuhn T (1962) The structure of scientific revolutions. The University of Chicago, USA

13. Project for public spaces. https://www.pps.org/article/roldenburg. Accessed 23 August 2020.

14. Morisson A (2018) A typology of places in the knowledge economy: towards the fourth place. Paper presented at International Symposium on New Metropolitan Perspectives, Reggio Calabria, 22-25 May 2018.

15. Castells M (1996) The rise of the network society. Wiley-Blackwell, United kingdom

16. Botsman R, Rogers R (2010) What's mine is yours: the rise of collaborative consumption. Harper Collins, New York

17. Waber B, Magnolfi J, and Lindsay G (2014). Workspaces that move people. Available via https://hbr.org/2014/10/workspa ces-that-move-people. Accessed 7 July 2016.

18. GBCSA (2013) The evolution of the office. Available via www.gbcsa.za. Accessed 27 November 2016.

19. Hardy B, Graham R, Stansall P et al (2008) Working beyond walls: the government as an agent of change. Crown, UK

20. Khasaba S, Afify M (2018) The development of office buildings design in Cairo and its influence on the external envelope based on a longitudinal analysis. Int J Sustain Build Technol Urban Dev 9(4):239-257

21. Sims D (2010) Understanding Cairo: the logic of a city out of control. The American University in Cairo Press, Cairo, New York. https://doi.org/10.5743/cairo/9789774164040.001.0001

22. De Lange M, and De Waal M (2019) The hacker, the city and their institutions: from grassroots urbanism to systemic change. The Hackable City: Digital Media and Collaborative City- Making in the Network Society. De Lange M, and De Waal M. Springer. Available via https://doi.org/10.1007/978-981-13-2694-3. Accessed at 7 July 2021.

23. Abdel-Rasoul A, Saad S, Amin M, Nazmy E (2017) Understanding publicness degree of Cairo's public spaces. Int J Sci Eng Res 8(12):1222-1234

24. Ahram online (2013) Faculty of Engineering at Cairo University suspends classes indefinitely, 10 December. Available via http://english.ahram.org.eg/NewsContent/1/0/88807/Egypt/0/Faculty-of-Engineering-at-Cairo-University-suspend.aspx. Accessed 17 April 2019.

25. Hillier B, Hanson J (1984) The social logic of space. Cambridge University Press, UK. https://doi.org/10.1017/CBO9780511 597237

26. Hillier B (2005) The art of place and the science of space. World Architecture: Special issue on Space Syntax

27. Bayat A (2010) Life as politics: how ordinary people change the Middle East. Stanford University Press, Stanford. https:// doi.org/10.5117/9789053569115

28. Sassen S (2011) Open source urbanism. Available via www.domusweb.it/en/op-ed/2011/06/29/open-source-urbanism. html. Accessed June, 2020.

29. Pollio A (2016) Technologies of austerity urbanism: the "smart city" agenda in Italy (2011-2013). Urban Geogr 37(4):514534. https://doi.org/10.1080/02723638.2015.1118991

30. Wiig A (2015) IBM's smart city as techno-utopian policy mobility. City 19(2-3):258-273

31. Dannestam T (2004) The theories and politics of entrepreneurial cities - a theoretical summing up and the next step forward. Paper presented at the 22nd Nordic Sociology Congress, Malmö

32. Ward K (2003) Entrepreneurial urbanism, state restructuring and civilizing 'New' East Manchester. Area 35(2):116-127. https://doi.org/10.1111/1475-4762.00246 
33. McNeil D (2016) Governing a city of unicorns: technology capital and the urban politics of San Francisco. Urban Geogr 37(4):494-513. https://doi.org/10.1080/02723638.2016.1139868

34. Peck J (2012) Austerity urbanism: American cities under extreme economy. City 16(6):626-655. https://doi.org/10.1 080/13604813.2012.734071

35. Harvey D (2012) Rebel cities: from the right to the city to the urban revolution. Verso, Brooklyn

36. Berger P (1963) An invitation to sociology: a humanistic perspective. Doubleday, United States

37. Foucault M (1975) Discipline and punishment: the birth of the prison. Gallimard, France. In: English edition: Foucault M (1995) Discipline and punishment: the birth of the prison (trans: Sheridan A). Vintage books, New York

38. Merkel J (2015) Coworking in the city. Ephemera 15(2):121-139

39. Moriset B (2014) Building new places of the creative economy: the rise of coworking spaces. Paper presented at 2 nd Geography of Innovation International Conference, Utrecht, 23-25 January 2014.

40. State Information Service (2016) Smart village, 24 April. Available via https://www.sis.gov.eg/Story/101112/Smart-Villa ge?lang=en-us\#: :text=Spread\%20over\%203\%20million\%20m, and\%20research\%20and\%20development\%20centers. Accessed 09Nov 2020.

\section{Publisher's Note}

Springer Nature remains neutral with regard to jurisdictional claims in published maps and institutional affiliations.

Submit your manuscript to a SpringerOpen ${ }^{\circ}$ journal and benefit from:

- Convenient online submission

- Rigorous peer review

- Open access: articles freely available online

- High visibility within the field

- Retaining the copyright to your article

Submit your next manuscript at $\boldsymbol{\nabla}$ springeropen.com 